\title{
FineCat: a Meeting Fostering Progress in Frontier Research and Sustainable Development from and within Sicily
}

\author{
Rosaria Ciriminna, ${ }^{a}$ Cristina Della Pina, ${ }^{b}$ Leonardo Palmisano, ${ }^{*, c}$ and Mario Pagliaro ${ }^{*, a}$ \\ a Istituto per lo Studio dei Materiali Nanostrutturati, CNR via U. La Malfa 15390146 Palermo, Italy \\ ${ }^{b}$ Dipartimento di Chimica Università degli Studi di Milano via Venezian 2120133 Milano, Italy \\ c "Schiavello-Grillone" Photocatalysis Group, DEIM Università degli Studi di Palermo viale delle Scienze \\ Ed. 690128 Palermo, Italy
}

Email: leonardo.palmisano@unipa.it (L. P.), mario.pagliaro@cnr.it (M. P.)

\begin{abstract}
Scientific meetings on topics of socioeconomic and environmental global relevance such as the "FineCat Symposium on heterogeneous catalysis for fine chemicals" held in Sicily between 2012 and 2017 may actively promote sustainable development and progress in frontier research from and within developing areas of the world.
\end{abstract}

Keywords heterogeneous catalysis, fine chemicals, FineCat, chemical industry

\section{Introduction}

Established after the publication of the 2011 Catalysis Science \& Technology "Heterogeneous catalysis for fine chemicals" themed issue co-edited by Hutchings and Pagliaro, ${ }^{[1]}$ the "FineCat-Symposium on heterogeneous catalysis for fine chemicals" was held for the first time in Palermo, Italy, on April 18-19, 2012. The conference venue was the 700 years old Steri Palace, hall of Palermo's University Rectorate.

Jointly organized by Italy's Research Council and Palermo's University, the meeting aimed to provide a new, high-level learning and networking opportunity amongst researchers working at the development of solid catalysts for the clean and economically viable production of fine chemicals.

Fine chemicals, polyfunctional molecules with specific properties imparting them high added value, have traditionally been synthesized via selective homogeneous synthetic methods. This is now changing as newly developed heterogeneous catalysis emerges as a convenient industrial tool capable to make the fine chemicals industry not only environmentally, but also economically, more sustainable. ${ }^{[1]}$

Furthermore, biomass is emerging as new industry's feedstock replacing oil and petrochemicals as raw material thereby closing the materials cycle making circular the chemical industry's processes. ${ }^{[2]}$

Eminent speakers at the FineCat meetings, including Hutchings, Reetz, Ananikov, Hashmi, Bianchini, Cole-Hamilton, Kaliaguine, Rothenberg, Beletskaya, Kappe, McQuade, Fornasiero, Grader, Debecker, Meireles-Torres, Mäki-Arvela and Abu-Reziq, recounted and anticipated in Sicily advances in catalysis later to become real processes benefiting the environment, society and the economy.

The idea for the meeting was born out of the aforementioned themed issue dedicated to Professor Michele Rossi, on the occasion of his retirement from the University of Milan, Italy, where his Group had given fundamental contributes to catalysis science and technology by developing, for instance, new gold catalysts for carbohydrate selective oxidation. ${ }^{[3]}$

Looking to the future, this study aims to show how progress in catalysis (and in heterogeneous catalysis, in particular) anticipated at an international chemistry meeting can actively promote sustainable development and progress in frontier research from and within developing regions.

\section{Progress in frontier research}

On April 18, 2012, in the presence of Professor Rossi, Professor Gadi Rothenberg, University of Amsterdam, opened the inaugural edition of the Symposium with a lecture on a simple and effective new method for predicting catalys performance (Figures 1 and 2). ${ }^{[4]}$

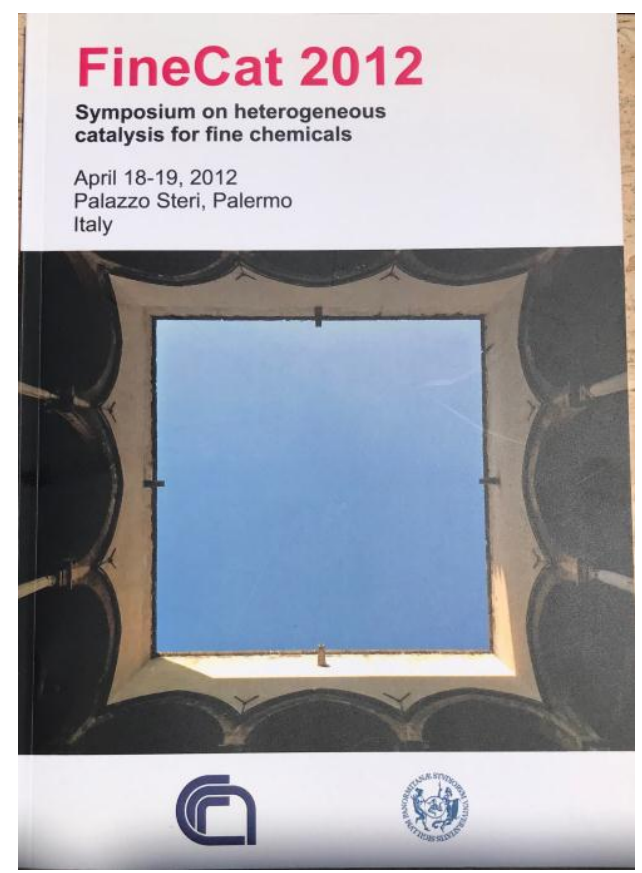

Figure 1 FineCat 2012, cover of the Book of Abstract.

He explained how, if we wish to screen a large number of catalysts (i.e., 100,000 catalysts every day at one second per catalyst rate) computational methods such as density functional theory (DFT) and semi-empirical quantum chemistry method are "out of game". This leads to a need of a fast and necessarily 

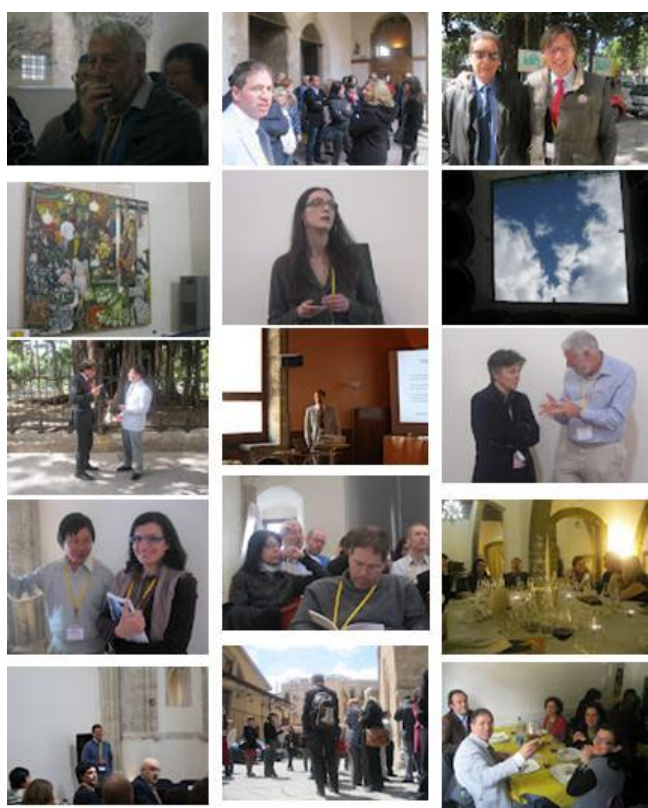

Figure 2 Snapshots from the first "FineCat-Symposium on heterogeneous catalysis for fine chemicals" held in Sicily, April 18-19, 2012.

unsophisticated approach for screening heterogeneous catalysts.

He then showed that heterogeneous catalysis can basically be modeled as an electronic interaction between molecules and a metal set of atoms even if the species are not involved molecular.

According to this approach, Professor Rothenberg continued, the atomic orbitals introduced by Slater ${ }^{[5]}$ in 1930 are simple and effective descriptors for metal's electron distribution. For example, he showed how to model adsorption and catalysis at the surface of a metal nanoparticle using only four descriptors/parameters for metal and four for the adsorbate. ${ }^{[6]}$

Along this path, Professor Rothenberg also showed how to use a statistics technique typically used in data mining for data analysis. The major effects of support, temperature, solvent and type of metals can be readily identified. Applied, for example, to the reduction of a carbonyl compound over a supported metal catalyst, the predicted and experimental yields are in surprising agreement: namely $85 \%$ of all predictions are correct. ${ }^{[7]}$

On the subsequent day, the vice chancellor for research at Cardiff University Graham Hutchings gave a remarkable talk on the latest developments using supported gold and gold palladium nanoparticles as heterogeneous catalysts. ${ }^{[8]}$

$\mathrm{He}$ firstly told the story of gold catalysis dating back to his days at $\mathrm{ICl}$ (Imperial Chemical Industries) in South Africa and then at the University of Witwaterstrand after which, in the early to mid 1980s. He ${ }^{[9]}$ and Haruta ${ }^{[10]}$ firstly predicted and then discovered that gold, when prepared as supported nanoparticles, is in fact an exceptionally effective redox catalyst, for example, very active for $\mathrm{CO}$ oxidation ${ }^{[10]}$ and acetylene hydrochlorination. ${ }^{[9]}$

Professor Hutchings explained how firstly almost no researcher believed in these results as this observation is counter intuitive since extended gold surfaces do not chemisorb oxygen, nor do they corrode (Figure 2).

Since then, however, there has been an explosion of interest in gold as a catalyst, ${ }^{[11,12]}$ and gold catalysis is now a major topic for both heterogeneous and homogeneous catalysis worldwide, as shown at FineCat 2012 by the presentations of Cristina Della Pina ${ }^{[13]}$ and Laura Prati ${ }^{[14]}$ who outlined a decade of research on gold-catalyzed oxidations at the University of Milan.

Anticipating subsequent advances in single-atom catalysis concerning also gold, ${ }^{[15]}$ Professor Hutchings underlined how recent aberration-corrected microscopy studies on the nature of the active site for $\mathrm{CO}$ oxidation had revealed that the active species may involve only $7-10$ gold atoms (Figure 3$).^{[16]}$

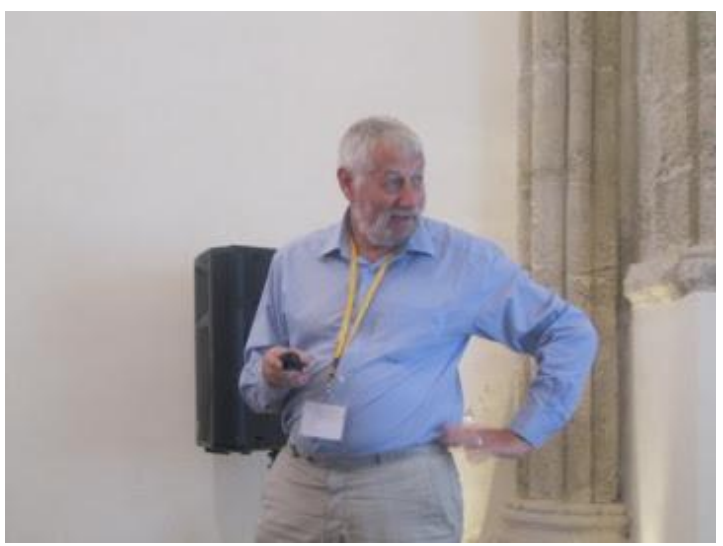

Figure 3 Professor Graham Hutchings giving a lecture on catalysis with gold and gold palladium nanoparticles at FineCat 2012, Palermo, April 18, 2012.

Professor Hutchings then showed how this advanced microscopy technique lately allowed his Group to identify the active, bi-layers of gold nanoparticles in oxidation catalysis, whereas traditional TEM images were completely misleading affording unresolved micrographs of both inactive and highly active gold catalysts. A few months after Palermo's meeting the world's first vinyl chloride monomer (VCM) plant using Hutchings' Au/Pd catalyst replacing highly toxic $\mathrm{HgCl}_{2} / \mathrm{C}$ catalyst, a full commercial reactor comprised of 790 reactor tubes and 1.6 tons of the gold catalyst, started operation in China.

At the end of the Symposium's second day, the University of Palermo's Rector, Roberto Lagalla, offered to the delegates a guided tour of the medieval Palazzo Steri, which also hosts the celebrated painting "La Vucciria" of Renato Guttuso.

Scientific exchange and networking were further eased by the informal style of the Symposium along with the unique milieu of both Palazzo Steri and the Cantine Florio of Marsala wines, where the Symposium gala dinner was offered, in a proper balance between science, art and entertainment.

Held on April 10-11, 2013 again in the venue of the Steri Palace and dedicated to the memory of University of Palermo's Professor Ines Donato, the second "FineCat-Symposium on heterogeneous catalysis for fine chemicals" opened with a presentation on flow chemistry approach to catalysis given by David Tyler McQuade, Professor at Florida State University and visiting scholar at Max Planck Gesellschaft Institute of Colloids and Interfaces in Berlin (Figures 4, 5 and 6). ${ }^{[17]}$

Professor McQuade showed how heterogeneous catalysis under flow has now reached a level, where massive production of drugs at low cost had become possible. He showed, for example, how 1,500 flow reactors could rapidly and economically afford artemisinin from dihydroartemisinic acid, meeting the world's demand of this powerful antimalaria drug.

$\mathrm{He}$ went on discussing the lbuprofen synthesis in flow developed in his labs, ${ }^{[18]}$ and anticipated the forthcoming publication (in collaboration with Seeberger) of artemisinin photochemical synthesis in flow using a continuous, divergent synthesis system coupled to continuous purification affording four anti-malarial active pharmaceutical ingredients in high 


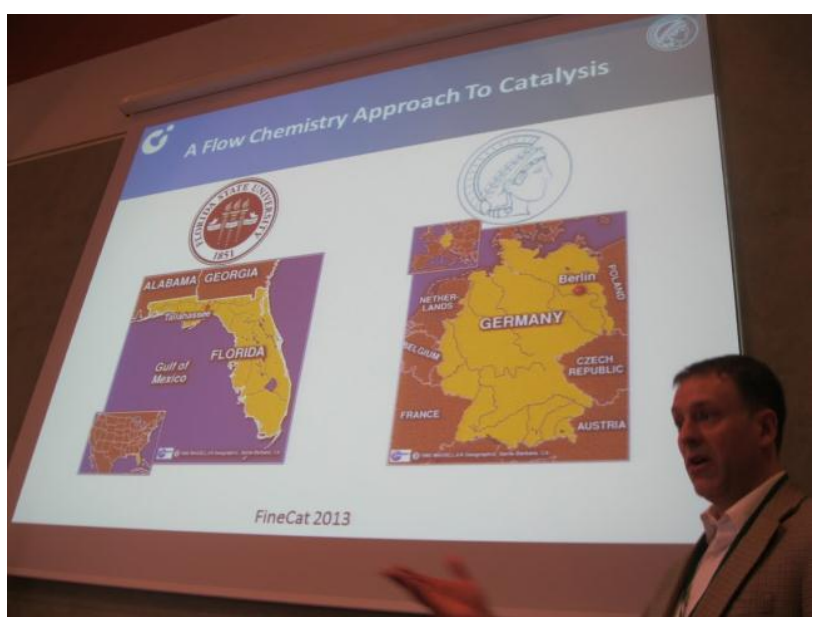

Figure 4 Professor David Tyler McQuade lecturing on the flow chemistry approach to catalysis at FineCat 2013, Palermo, Palazzo Steri, April 10, 2013.

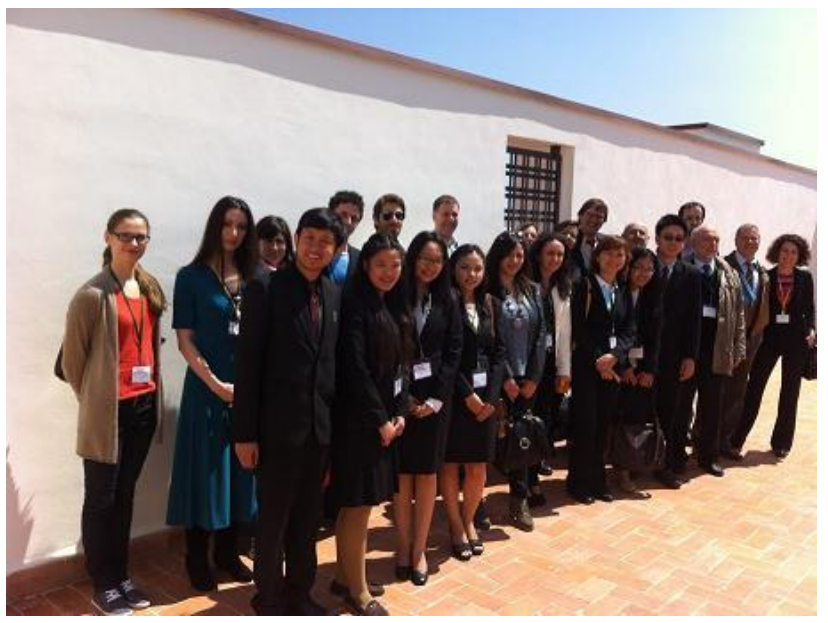

Figure 5 Some of the participants at FineCat 2013, Palermo, Palazzo Steri, April 10—11, 2013.

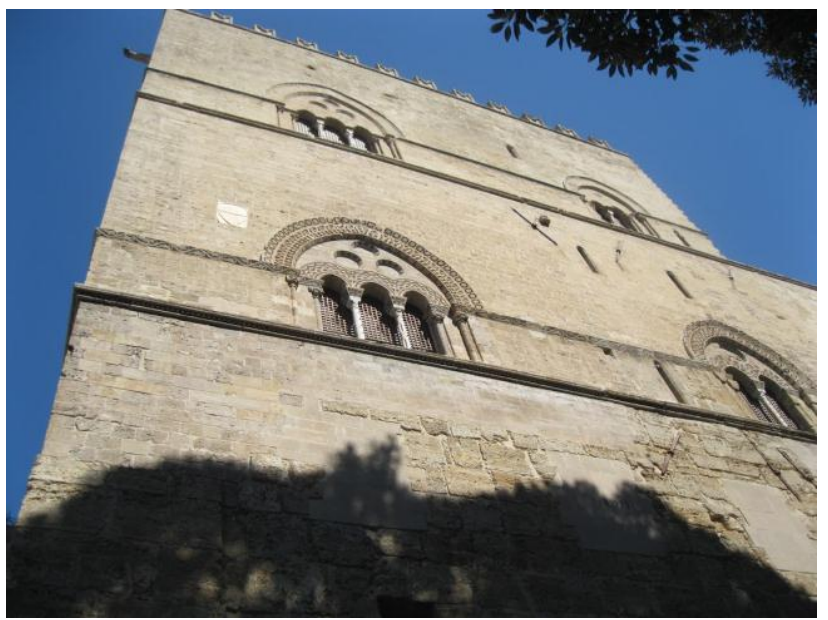

Figure 6 Palazzo Steri, site of five out of six FineCat symposium editions, photographed during FineCat 2013, on April 10, 2013.

purity and yield. ${ }^{[19]}$

Microreactor technology using traditional supported reagents, he further added, is not feasible since fluid flows around conventional polymer beads, and not through them. This requires the use of microcapsules and other materials with proper morphology, porosity, surface area and chemical stability aptly tailored for this powerful synthetic technique. ${ }^{[20]}$

Professor McQuade concluded his presentation showing the remarkable results obtained in flow with three solid catalysts (proline, copper- and zinc-based materials).

The presentation given the subsequent day by Claudio Bianchini, Italy's prominent chemist former director of Italy's Research Council main chemistry institute, focused on the use of platinum and palladium nanoparticles as highly efficient electrocatalysts for the electrochemical valorization of alcohols in fuel cells. ${ }^{[21]}$

He showed how his group in Florence developed a number of reproducible synthetic strategies to prepare catalysts suitable for the catalytic oxidation of low cost renewable alcohols such as ethanol and glycerol affording in a single conversion valued chemicals and useful energy in the form of electricity and low temperature heat. ${ }^{[22]}$

These catalytic materials, he concluded, are mature for making bioalcohol-based fuel cells a commercial reality in specific market applications.

The former head of University of Naples' industrial chemistry Department Elio Santacesaria concluded the Symposium presenting the use of biobased glycerol as new raw material in the production of chlorohydrins and tert-butylethers (GBTE). ${ }^{[23]}$

Professor Santacesaria firstly showed how the catalytic process developed by his group, using biodiesel as extracting agent, efficiently affords GBTE in high yield, directly mixed with biodiesel and greatly improving the properties of the resulting biofuel mixture. ${ }^{[24]}$

He then showed evidence of the reaction mechanism, by which glycerol is selectively converted into mono and 1,2-dichlorohydrin by reaction with gaseous hydrochloric acid in the presence of catalytic amount of carboxylic acids. ${ }^{[25]}$

Not only epichlorohydrin can be isolated in almost quantitative yield but, using different carboxylic acid, also the monochlorohydrin can be isolated in high yields. The latter product is a direct precursor of glycidol, namely a valued fine chemical currently obtained by epoxidation of allyl alcohol.

The presentation ended with photographs of Professor Santacesaria and co-workers next to the pilot plant realized in Malaysia using the new technology for glycerol hydrochlorination developed by his team and commercialized by an Italy's company.

Inaugurated by a speech of Palermo's University Pasquale Agozzino dedicated to the memory of the late Professor Vincenzo Romano-for almost 4 decades eminent professor of analytical chemistry at the same University-the third FineCat Symposium took place on April 2-3, 2014 featuring the invited lectures of the president elect of the European Chemical Society (EuChemS), David Cole-Hamil ton as well as of eminent chemists Serge Kaliaguine, Paolo Fornasiero and Jose Antonio Lopez-Sanchez.

On April 2, 2014, University of St. Andrews' Professor David Cole-Hamilton opened the meeting with a lecture on flow catalysis using supported homogeneous catalysts, an hot topic also in industry, where a number of pharmaceutical and CMO (contract manufacturing organizations) already make use of manufacturing processes carried out under flow (Figure 7). ${ }^{[6]}$

He described successful flow systems using catalysts supported on solids in ionic liquids or in the reaction product, where the substrate and product flow as liquids or dissolved in supercritical fluids. 


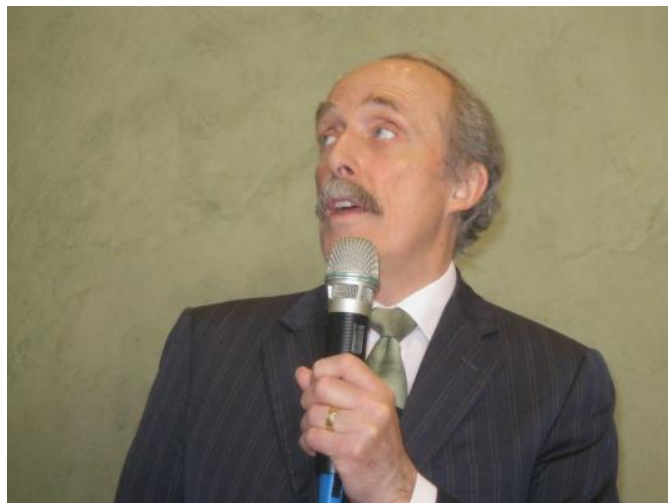

Figure 7 Professor David Cole-Hamilton giving a lecture on homogeneous and heterogeneous catalysis under flow at FineCat 2014, Palermo, Palazzo Steri, April 2, 2014

Reactions covered included the hydroformylation of alkenes to give linear aldehydes, metathesis of methyl oleate, asymmetric hydrogenation to give a product which is a solvent free pure enantiomer and the first ever hydrogenation of amides to amines, ${ }^{[27]}$ a particularly difficult reaction, of considerable interest in the pharmaceutical industry.

Professor Cole-Hamilton ended his presentation citing an article of Cornforth dating back to 1975, the same year John Cornforth was awarded the Nobel Prize in chemistry: ${ }^{[28]}$

It does, for example, no good to offer an elegant, difficult and expensive process to an industrial manufacturing chemist, whose ideal is something to be carried out in a disused bathtub by a one-armed man who cannot read, the product being collected continuously through the drain hole in $100 \%$ purity and yield.

This is in practice what happens using a Rh-MeDuPHOS catalyst immobilized onto alumina through phosphotungstic acid employed by Cole-Hamilton's team in the continuous, solventless hydrogenation of prochiral dibutyl itaconate to dibutyl (S)-(-)-methylsuccinate at ambient temperature under 5 bar $\mathrm{H}_{2}$ at $0.2 \mathrm{dm}^{3} \mathrm{~min}^{-1}$ and substrate $0.05 \mathrm{~mL} \mathrm{~min}^{-1}$ flow rate, in which the product is recovered directly from the flow system. ${ }^{[29]}$

On the same day, Serge Kaliaguine described the chemical behaviour of newly prepared Ti-SBA-15 silicas in epoxidation catalysis (Figure 8). ${ }^{[30]}$

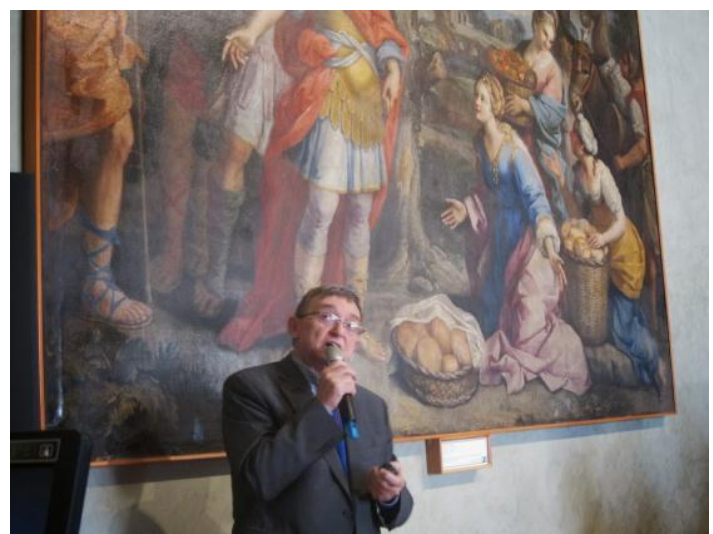

Figure 8 Professor Serge Kaliaguine giving a lecture on mesoporous titania-modified silicas as epoxidation catalysts at FineCat 2014, Palermo, Palazzo Steri, April 2, 2014.

The renowned Université Laval's Professor of chemical engineering showed his team's approach to post-synthesis low coordination grafting of titanium in mesostructured silica, making use of a chelate titanium precursor generated in situ by action of acetyl acetonate on tetraethyl orthotitanate $\left(\mathrm{CH}_{3} \mathrm{CH}_{2} \mathrm{CH}_{2} \mathrm{O}\right)_{4} \mathrm{Ti}$.

Compared with those produced by the more usual one-pot synthesis, the new solid catalysts thereby obtained employed in cyclohexene epoxidation by tert-butyl hydroperoxide are not only more active but also more stable.

In detail, the Ti-SBA-15 catalysts synthesized using non calcined SBA-15 materials show an increased resistance to catalytic deactivation with the Ti-SBA-15 material aged at $140{ }^{\circ} \mathrm{C}$ with high $(6 \%) \mathrm{Ti}$ loading being fully reusable in 3 consecutive epoxidation reactions. ${ }^{[31]}$

On the subsequent day, the Symposium was opened by University of Trieste's Professor Paolo Fornasiero, who described the nanochemistry approach to designing powerful catalysts by manipulation of clusters and nanocrystals as building blocks (Figure 9). ${ }^{[32]}$

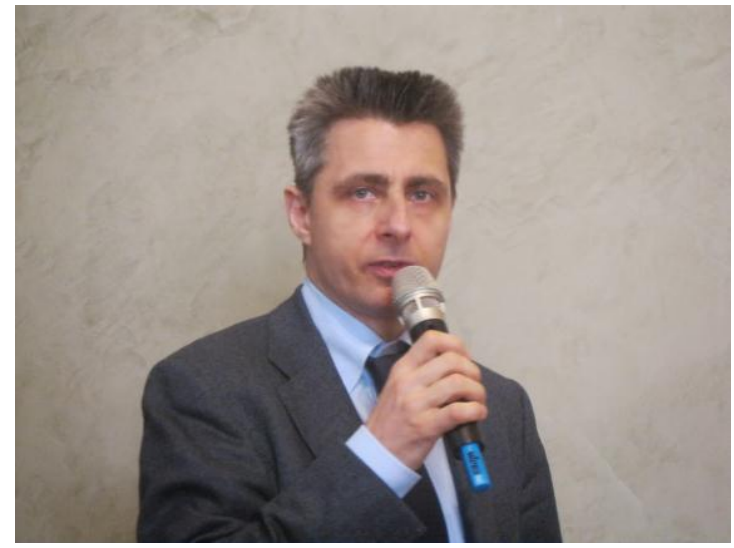

Figure 9 Professor Paolo Fornasiero lecturing on the design of cluster and nanocrystal catalysts as building blocks at FineCat 2014, Palermo, Palazzo Steri, April 3, 2014.

Gone are the days, he explained, in which chemists functionalized at random solid materials with metal or molecular catalysts and then studied their behaviour. In a true nanochemistry approach to nanomaterial synthesis, core-shell architectures are synthesized, in which noble metal nanoparticles are incorporated within mesoporous metal oxide shells such as $\mathrm{CeO}_{2}, \mathrm{TiO}_{2}$ and $\mathrm{ZrO}_{2}$.

The "Nano-Lego" chemistry is a powerful and scientifically exciting approach by which, he insisted, catalyst design from concept to industrial process becomes possible. ${ }^{[33]}$

The interface between the two phases is maximized and there is additional protection of the metal NPs towards aggregation, resulting in considerable improvement of the activity in several catalytic processes.

Today, he continued his lecture, we plan the fabrication of solid catalysts in which the active species is thoroughly caged in robust oxide structures whose shape is designed according to application requirements. This will have a profound impact also on the synthesis of fine chemicals.

Examples include the electrooxidation of renewable susbstrates such as ethylene glycol and glycerol on the $\mathrm{Pd}-(\mathrm{Ni}-\mathrm{Zn}) / \mathrm{C}$ anode of fuel cells, ${ }^{[34]}$ and monodisperse $\mathrm{Ni}, \mathrm{Pt}$, and $\mathrm{Pd}$ nanoparticles dispersed on high-surface-area ceria or alumina supports, wherein the rate of $\mathrm{CO}$ oxidation on ceria is largely enhanced at the nanosized interface. ${ }^{[35]}$

The presentation by the head of the University of Liverpool's Microbiorefinery, Jose Antonio Lopez-Sanchez, focused on the opportunities and challenges for chemocatalytic conversion of biomass into value added chemicals, including fine and specialty chemicals (Figure 10). ${ }^{[36]}$ 


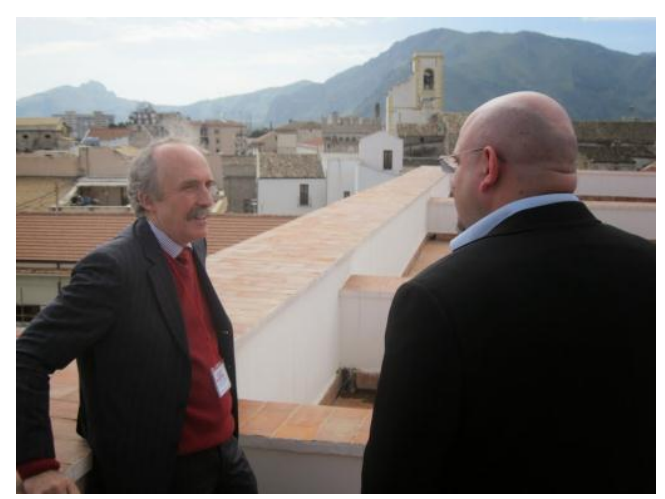

Figure 10 David Cole-Hamilton and Tony Lopez-Sanchez during a FineCat 2014 break on the rooftop terraces of Palazzo Steri, Palermo, April 3, 2014.

Critically putting arguments in a wider socioeconomic framework, Professor Lopez-Sanchez explained why the development of new efficient and economically viable routes to chemicals from lignocellulosic biomass is the most important single challenge that we face in order to commercialize renewable chemicals on the required large scale to compete with petrochemicals.

If we witness so little practical innovation despite a huge scientific production, he added, this is due to lack of industrial involvement as well as to a lack of customer-centric view. If we want to succeed in seeing our processes go real, he concluded, we should adopt a functional-oriented view by which, for example, the functional polymers we make from biomass are even more performing than the petrochemical counterparts.

$\mathrm{He}$ then showed how catalysis and new chemistry technologies such as high-throughput instrumentation, microwaves and photocatalysis, widely investigated in his group's current research, actually contribute to the development of these new routes within a changing multidisciplinary background where biotechnology solutions are finding an increasing role. ${ }^{[37]}$

"It is in places such as this one." said Professor Manfred Reetz in a speech opening the social dinner of the 4th edition of the "FineCat Symposium on heterogeneous catalysis for fine chemicals" at the Tasca d'Almerita estate in central Sicily, "that we understand that chemistry is not the most important thing in life."

Dedicated to the memory of University of Palermo's Professor Roberto Triolo, the symposium took place on April 8-9, 2015 in Palermo's Palazzo Steri featuring presentations given by prominent chemistry scholars Manfred Reetz, Irina Beletskaya, C. Oliver Kappe, Pedro Maireles-Torres, Rodrigo de Souza, Damien Debecker, Päivi Elisa Mäki-Arvela and Sébastien Paul.

Manfred Reetz, Hans-Meerwein-Research-Professor, Marburg University and previously Director at the Max-PlanckInstitut für Kohlenforschung in Mülheim for almost 20 years, presented the impressive outcomes of research in the directed evolution of enantioselective enzymes, as a source of powerful catalysts for asymmetric reactions (Figure 11). ${ }^{[38]}$

In the 1990s, Reetz' team firstly stabilized and greatly enhanced the lipase activity by encapsulating the enzymes in ORMOSIL matrices, ${ }^{[39]}$ and then presented proof-of-principle of directed evolution of stereoselectivity as a protein engineering technique comprising repeating cycles of gene mutagenesis, expression and screening for a given catalytic property. Targeting massive industrial adoption of biocatalysis, the aim was and is to expand enzyme limited substrate scope, and poor stability under operating conditions. ${ }^{[40]}$

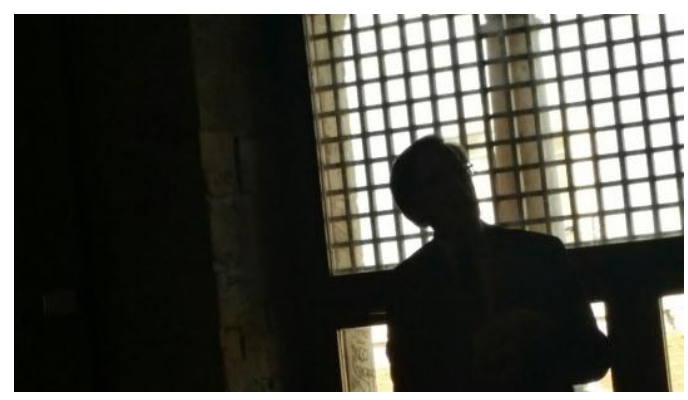

Figure 11 Professor Manfred Reetz giving a lecture on directed evolution of enantioselective enzymes as a source of powerful catalysts for asymmetric reactions at FineCat 2015, Palermo, Palazzo Steri, April 8, 2015.

Since then, Professor Reetz continued recounting the tour de force that has brought directed evolution, from the original discovery in 1997, to become fast and reliable, evaluated for forthcoming clean industrial syntheses of enantiopure molecules.

The latest results including hydrolases, reductases, and $\mathrm{P} 450$-catalyzed stereo- and regioselective $\mathrm{CH}$-activating oxidative hydroxylation of simple and complex organic compounds were thus presented in Palermo, with emphasis on transformations not possible using the best synthetic catalysts known to date.

In her presentation, Professor Irina Beletskaya, Academician of the Russian Academy of Sciences and former president of the Division of Organic Chemistry of IUPAC, firstly compared the homogeneous and heterogeneous catalysis with several metals in different reactions of relevance to fine chemistry, and then considered the asymmetric catalysis by immobilized Broensted and Lewis acids in Friedel-Crafts, Michael, Pudovic and other important reactions on asymmetric reactions (Figure 12). ${ }^{[41]}$

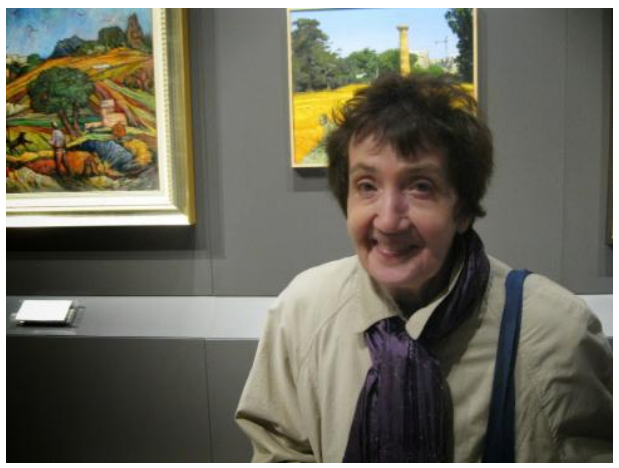

Figure 12 Professor Irina Beletskaya during tour of Palazzo Steri guided by Palermo's University Rector after her lecture on the transitions from homogeneous to heterogeneous catalysis in fine organic synthesis at FineCat 2015, Palermo, Palazzo Steri, April 9, 2015.

Professor Beletskaya thus explained how "nanosalt" catalysis taking place in solution is involved in most homogeneous and heterogeneous $\mathrm{C}-\mathrm{C}$ and $\mathrm{C}$-heteroatom bond formation reactions in organic synthesis, with pool of active metal species that contribute to the product formation. ${ }^{[42]}$

Best known for her studies carried out at Moscow State University's organoelement chemistry laboratory on aromatic reaction mechanisms, as well as work on carbanion acidity and reactivity, Professor Beletskaya has developed some of the first methods for carbon-carbon bond formation using palladium or nickel catalysts, and extended these reactions to work in aqueous media. 


\section{Meeting Hot}

The impressive achievements in catalysis for green chemistry processes led one co-chairman of the Symposium to ask whether Russian chemical companies were considering to uptake new green chemistry routes developed in Russian labs.

"Many chemical companies of the former USSR," responded the Editor-in-Chief of the Russian Journal of Organic Chemistry 'are located in Donbass and close regions'. "I am sure that once the situation will settle down, Russian chemical companies will adopt green chemistry process on large scale."

On the subsequent day, Professor C. Oliver Kappe in Institute of Chemistry, University of Graz, Austria, described the contributions of his team in the field of catalytic synthesis of active pharmaceutical ingredients (APIs) and other key intermediates under flow (Figure 13). ${ }^{[43]}$

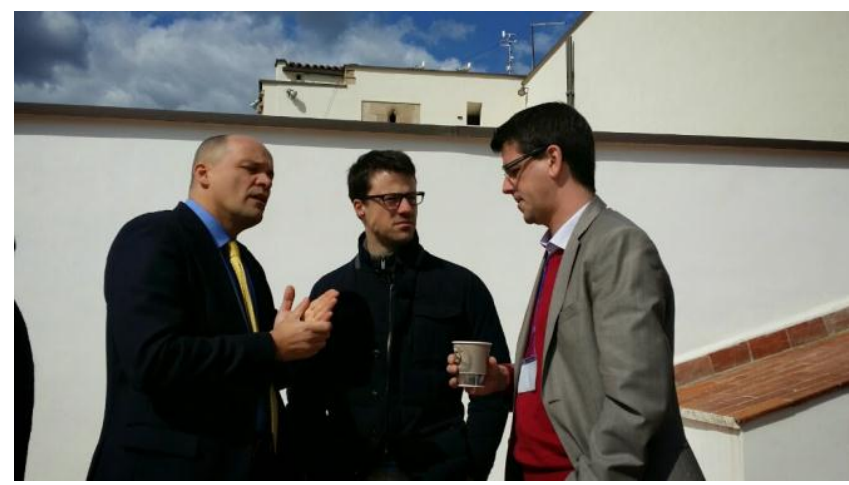

Figure 13 Professors C. Oliver Kappe, Damien Debecker, and Sébastien Paul (from left to right) during a FineCat 2015 break on the terraces of Palazzo Steri, Palermo, April 9, 2015.

Professor Kappe explained how fine chemicals, such as drug substances and APIs, being considerably more complex than commodity chemicals, usually require numerous and widely diverse reaction steps for their synthesis, making versatile and reconfigurable multipurpose batch reactors the technology of choice for their preparation.

Through numerous examples, he showed how the advantages of continuous flow processing are increasingly being appreciated and practically exploited by the main API suppliers of the pharmaceutical industry.

Highly atom efficient and process intensified catalytic chemical transformations, Professor Kappe emphasized, are particularly useful for the synthesis of APIs or key intermediates that are often too hazardous to be executed in a batch reactor. $^{[44]}$

How these concepts are used for example in Brazil was elucidated by Professor Rodrigo de Souza, Federal University of Rio de Janeiro, offering a Brazilian perspective on the "Medicines for all" drugs making project presented by Professor Tyler McQuade at FineCat $2013,{ }^{[17]}$ in which the remarkable results on the continuous flow technology using immobilized enzymes to synthesize important APIs were presented. ${ }^{[45]}$

The continuous production of APIs using catalytic reactions under flow, Professor De Souza further argued, is especially well suited for the Brazilian health system needs.

In particular, he added, through reusable immobilized amine transaminase and lipase enzymes, ${ }^{[46]}$ wherein the continuous flow technology ensures both efficient mass and heat transfer preventing product inhibition due to insufficient product removal from the microenvironment of the enzyme due to mass transfer limitations.

"Catalysis is living a renaissance", opened his lecture, Professor Sébastien Paul, Ecole Centrale de Lille, France, emphasizing its central role in the emerging biorefinery. ${ }^{[47]}$

$\mathrm{He}$ then presented the impressive "Realcat" platform recently installed in Lille. The development of new, advanced platforms where to carry out expedited research on heterogeneous catalysis, he further explained, is of great practical relevance, particularly in the context of the biorefinery where oxygenated substrates are to be rapidly and selectively converted.

Such an oleochemical platform devoted to the production of biofuels and chemicals from vegetable oils and fats was presented by Professor Pedro J. Maireles Torres, University of Malaga, Spain, who described several new different strategies to attain high yields of biodiesel by using solid catalysts, including those developed by his team. ${ }^{[48]}$

Professor Päivi Elisa Mäki-Arvela, Åbo Akademi University, Finland, presented the successful heterogeneously catalyzed synthesis of Dioxinol (a drug) starting from naturally occurring monoterpenoid verbenol oxide reacted with benzaldehydes over metal modified zeolites. ${ }^{[49]}$

Presenting new developments concerning sol-gel catalysts for fine chemicals synthesis, Professor Damien Debecker, Université catholique de Louvain, Belgium, described the use of sol-gel immobilized transaminase for the enantioselective synthesis of chiral amines. ${ }^{[50]}$

The versatile sol-gel process was adapted by his team in order to produce, in one step only, self-standing macrocellular silica monoliths. The enzyme was immobilized on the structured silica monoliths both by adsorption, and by covalent grafting using amino-functionalized silica monoliths and glutaraldehyde as a coupling agent.

The resulting solid catalyst was successfully used for the continuous flow kinetic resolution of a chiral amine, 4-bromo-a-methylbenzylamine with full retention of the enzyme activity and enantioselectivity, but with enhanced stability both on stream and during storage.

Results anticipated in Palermo, and subsequently published featuring on the cover of a catalysis journal, ${ }^{[1]}$ paved the way to the successful development of an environmentally friendly process for chiral amines production resolving the main problem with conventional polymer beads lamented by Tyler McQuade at FineCat 2013 (see above).

Inaugurated by a welcome address of former Palermo's University Professor Giulio Deganello, founder of Palermo's chemistry Institute of Italy's Research Council, the 5th FineCat was held on April 6-7, 2016 in the Sala delle Capriate of the Steri Palace, featuring the invited lectures of Valentine Ananikov and Bert Sels (Figure 14).

Professor Valentine P. Ananikov in Russian Academy of Sciences in Moscow discussed heterogeneous catalysis "in the eyes of fine organic chemists" (Figure 15). ${ }^{[52]}$

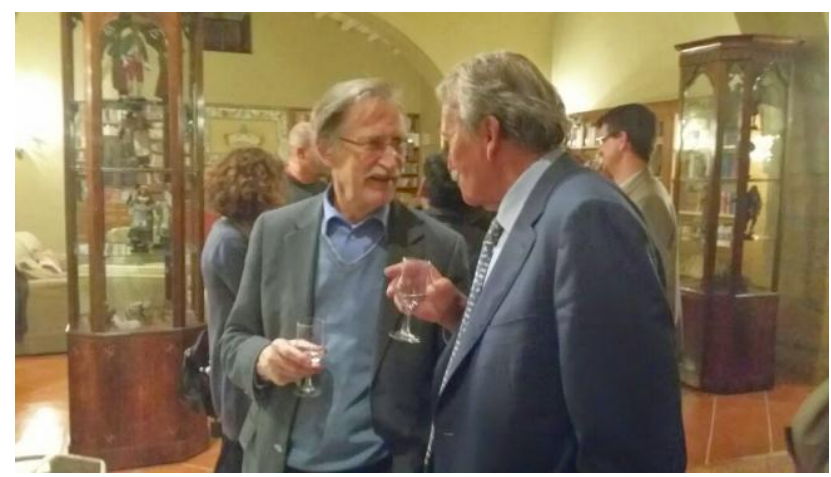

Figure 14 Professors Manfred Reetz and Giulio Deganello, FineCat 2015 social dinner, Tenuta di Regaleali, Sicily, April 9 , 2015. 


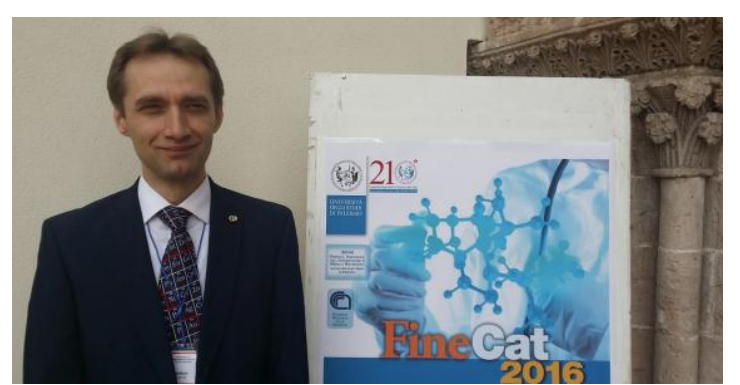

Figure 15 Professor Valentine P. Ananikov in Russian Academy of Sciences at FineCat 2016, Palermo, Palazzo Steri, April 6, 2016.

In his presentation, Zelinsky Institute of Organic Chemistry's Professor Ananikov targeted the construction of efficient and selective catalytic systems in light of his team's recent discoveries that homogeneous catalytic reactions are in fact due to "cocktail"-like systems, namely to participation of different metal species in the catalytic transformation.

In other words, homogeneous catalytic reactions, traditionally ascribed to monometallic active species, are in fact due to multicomponent reaction mixtures containing a number of metal species in solution. ${ }^{[53]}$ However, heterogeneous catalysis often involves formation of a number of active species that possess dynamic properties and interconversions on the surface.

The new strategies to reducing the cost of metal catalysts, devise leach-proof synthetic strategies and use easily available metal precursors, he explained, focus on the chemical tuning of said dynamic and adaptive "cocktail" of catalytic species, as well as on what he called the "non-innocent nature of carbon support in metal/carbon catalysts". ${ }^{[54]}$

One of the example presented is the design of a more efficient and more selective $\mathrm{Pd} / \mathrm{C}$ catalyst for synthetic applications. The latter material indeed is perhaps the commercial catalyst most frequently employed by the fine chemical industry for the synthesis of fine chemicals, pharmaceuticals, biologically active species and natural product derivatives.

His team recently discovered the crucial role of the structure of the carbon support, which governs the formation of $\mathrm{Pd} / \mathrm{C}$ systems and their catalytic activity through the surface defects and their gradients and variations across the surface area. ${ }^{[54]}$

Suddenly, it became possible to synthesize carbon material with specific types of defects as a support, preparing a new $\mathrm{Pd} / \mathrm{C}$ catalyst under mild conditions, controlling the catalyst evolution during the catalytic reaction with the desired molecular level tuning of $\mathrm{Pd} / \mathrm{C}$ active sites.

Heterogeneous catalysis has an outstanding unexplored potential for fine organic synthesis applications, concluded the RAS academician citing the last work of Balandin, the father of the Multiplet theory of catalysis, for whom the time was already ripe in the late 1960s "for the creation of a single theory of catalysis $\cdots$ a necessity and is particularly important for finding the principles that will allow anticipation of catalytic effects."

Professor Bert Sels in Katholieke Universiteit Leuven in Belgium, one of the world's leading chemistry scholars in biomass conversion into valued molecules, discussed how shape selective zeolites as well as zeolites and structured mesoporous silicas functionalized with single-site $\mathrm{Sn}$ catalytic centers tetrahedrally incorporated can be used as a highly effective heterogeneous Lewis acid catalysts in a wide range of sugar and other biomass-derived substrates conversions (Figure 16). ${ }^{[55]}$

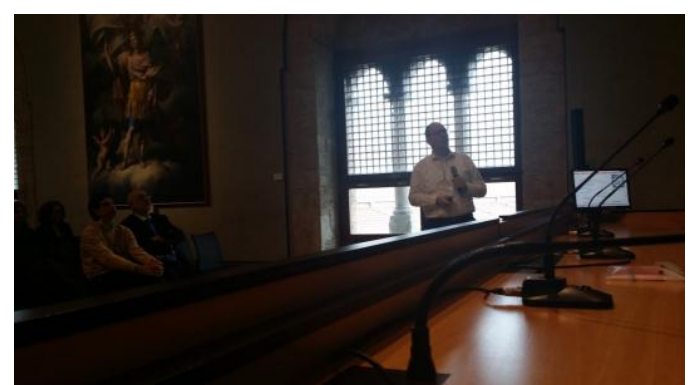

Figure 16 Professor Bert Sels giving a lecture on biomass conversion into valued molecules using Lewis acid catalysis with tin-modified silicas and zeolites at FineCat 2016, Palermo, April 7, 2016.

Professor Sels continued to show how tetrahedral Sn built into microporous silica frameworks such as zeolites and structured mesoporous silica is a superior heterogeneous Lewis acid catalyst in several condensation reactions affording new routes to various glyoxyl acids and cyclic lactones in the context of biomass conversion. ${ }^{[56]}$

Professor Sels showed how contemporary characterization tools were used to un-ravel the catalytic active site identity and, thus, optimization, of their nanochemistry aimed at maximizing their selective activity. Showing for example the importance of confinement of the active pocket in liquid phase catalysis, his team has shown how different $\mathrm{Sn}$-based catalysts with various pore sizes employed in the conversion of tetrose sugars to four-carbon a-hydroxy acid esters afford different product distribution depending on the size of the catalyst pores. ${ }^{[57]}$

Catalysts containing mainly mesopores, such as Sn-MCM41 or Sn-SBA-15, prefer the production of more bulky 4-methoxy-2-hydroxybutanoate (MMHB), whereas microporous catalysts such as $\mathrm{Sn}-\beta$ or $\mathrm{Sn-MFI}$ favor the production of methyl vinyl glycolate MVG. The effect is further enhanced by the reaction temperature, eventually selectively affording useful functional polyester building blocks depending on the catalyst employed.

Professor Sels concluded that biomass conversion is an exciting research area with a lot of unexplored terrain, in which new molecules and their heterogeneously catalyzed synthetic routes await to be discovered, requiring in its turn fundamental knowledge with regard to active sites and insight in the reaction mechanisms.

The 6th and last edition of the FineCat Symposium was held at Sicily's Royal Palace in Palermo on April 5, 2017. The Palace is the oldest royal residence in Europe. It was the seat of the Kings of Sicily during the Norman domination and has served ever since as the main seat of power for all rulers of Sicily, up to becoming Seat of the Sicilian Parliament in 1947.

The scientific works were opened by Professor Gideon S. Grader, Dean of Technion's Chemical Engineering Department since 2016 and Founding Director of the Nancy and Stephen Grand Technion Energy Program (Figure 17). ${ }^{[58]}$

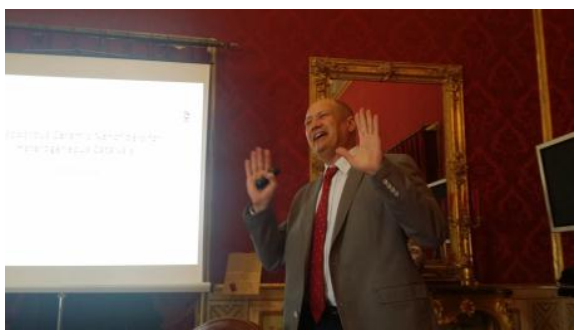

Figure 17 Professor Gideon Grader giving a lecture on mesoporous ceramic nanofibers for heterogeneous catalysis at FineCat 2017, Palermo, Palazzo Reale, 5 April 2017. 


\section{Meeting Hot}

The mechanisms discovered by his Group offer the possibility to create by electrospinning unique mesoporous core-shell nanostructured materials with specific properties, an highly desirable finding which facilitates new possibilities and applications in all fields of heterogeneous catalysis due to the combination of high surface to volume ratio and low mass transfer resistance to and from the catalytic sites.

In closer detail, Professor Grader anticipated in his Palermo's presentation how to synthesize nanometer-sized ceramic fibers with unique core-shell structure, consisting of an inner mesoporous $\mathrm{Fe}-\mathrm{Al}-\mathrm{O}$ core with an outer Fe-rich shell, using electrospinning followed by a controlled thermal treatment.

A few weeks after the meeting, the general mechanism of core and shell formation outlined and confirmed by his team, which enables, depending on heating rates, to obtain unique mesoporous nanofibers with or without shells, was published. ${ }^{[59]}$

A. Stephen K. Hashmi, Professor of organic chemistry and vice Rector for research at Heidelberg University, Germany, gave a fascinating lecture on new aspects of gold catalysis applied to the synthesis of a variety of functional products. ${ }^{[60]}$

As one of the world's leading scholars in gold catalysis, he explored since the early 2000s when he discovered that $\mathrm{AuCl}_{3}$ effectively mediates $\mathrm{C}-\mathrm{C}$ and $\mathrm{C}-\mathrm{O}$ couplings under remarkably mild conditions. ${ }^{[61]}$ Professor Hashmi described the latest findings concerning the new synthetic methods to access both gold(I) and gold(III) catalytic species, the identification of highly reactive catalysts, and the development of goldcatalyzed reactions including additions to allenes and alkenes, benzannulations, cycloisomerization, rearrangement as well as oxidation and reduction reactions (Figure 18).

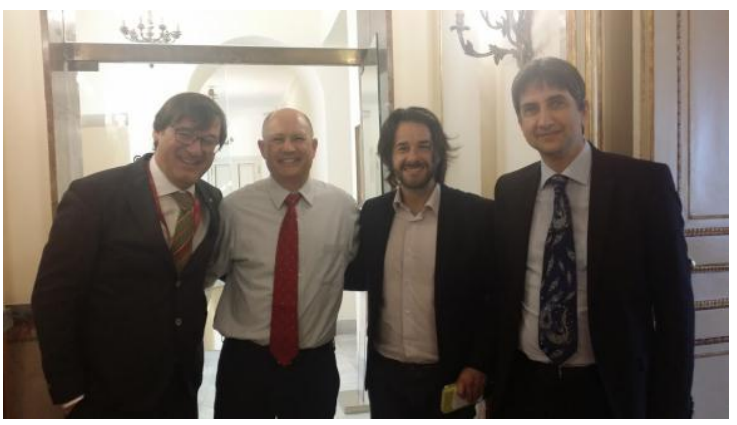

Figure 18 Mario Pagliaro, Gideon Grader, Giampiero Trizzino, Stephen K. Hashmi (from left to right) during a pause at FineCat 2017, Palermo, Palazzo Reale, 5 April 2017.

Already used for the production of bulk chemicals such as vinyl chloride monomer, gold catalysis is poised to be introduced in the production of the basic ingredients of a wide variety of valued added products ranging from pharmaceuticals through liquid crystals and organic light emitting diodes (OLED) for computer, TV and mobile phone screens.

"I can tell you that when I meet industrial researchers at their production sites". Professor Hashmi answered a question on practical applications in the pharmaceutical and fine chemical industries, "They make all sort of questions as if they were using and studying gold catalysis since years".

How to bridge homogeneous and heterogeneous catalysis was shown by Professor Raed Abu-Reziq, Hebrew University of Jerusalem, perhaps giving the most suited comprehensive conclusion to the 6 editions of FineCat. ${ }^{[62]}$

Professor Abu-Reziq's team approach exploits the sol-gel microencapsulation process versatility in its fullness to afford nano- and microreactors, magnetically separable silica microreactors and supports with well-defined nanostructures.
In brief, Professor Abu-Reziq showed how ionic liquids (IL), polyethylene glycol (PEG) or deep eutectic solvents (DES) can be encapsulated within silica shells, thereby particulating ionic liquids, DES or PEG and converting them in powder form (Figure 19).

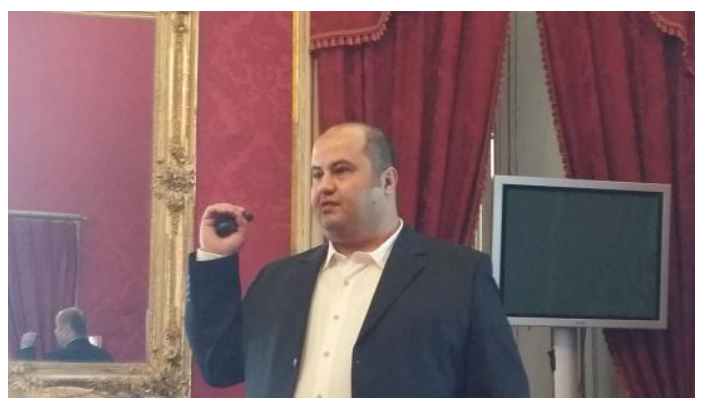

Figure 19 Professor Raed Abu-Reziq giving his lecture on nanostructured materials, nano-and microreactors as platform materials for heterogeneous catalysis at FineCat 2017, Palermo, Palazzo Reale, 5 April 2017.

The microencapsulated ionic liquids, DES or PEG, including at times $\mathrm{Fe}_{3} \mathrm{O}_{4}$ nanoparticles to produce magnetically separable nanocatalysts, ${ }^{[63]}$ are used to further control the selectivity and reactivity of co-encapsulated metal nanoparticle or organometallic catalysts.

The remarkable results presented concerned key reactions such as stereoselective hydrogenation, hydroformylation, $\mathrm{C}-\mathrm{C}$ bond formation, hydrosilylation and hydroaminomethylation, some of which have not been published yet.

All can be carried out heterogeneously using recyclable sol-gel microencapsulated chiral complexes of $\mathrm{Ru}$ and $\mathrm{Rh}$ (c-Ru/MNP@ $\mathrm{SiO}_{2}$ and c-Rh/PEG@SiO ${ }_{2}$ ), Pt/PEG@SiO ${ }_{2}$, and Pd/BMIm-PF6@SiO , and NHC-Rh/MNP@IL-SiO ${ }_{2}$, respectively, thereby showing evidence of the large application potential of new generation sol-gel catalysts for the fine chemical industry.

\section{Outlook and Perspectives}

Between 2012 and 2017, Sicily hosted some of the world's most prominent chemists lecturing at the "FineCatSymposium on heterogeneous catalysis for fine chemicals". Delegates from over 15 countries, from Norway through Thailand, testified to the truly international nature of the meeting, whose topic, namely the synthesis of the most valued chemicals through solid (molecular, metal and bio) catalysts, is at the core of the green technology transition of one of the most important sectors of the global manufacturing industry.

In his words of greeting to the delegates of FineCat 2017, Member of the Parliament of Sicily Giampiero Trizzino emphasized the importance to host a high-level scientific meeting on clean technology in Sicily's Parliament because tomorrow's Sicily will be known for its practical achievements in renewable energy and the bioeconomy.

Sicily is Italy's largest and least affluent region. The gross domestic product (GDP) per capita barely exceeded 17,000 EUR in $2017(€ 17,375)$ when, for comparison, the GDP per capita in Italy's second largest region approached $€ 37,000$. ${ }^{64]}$

Furthermore, approximately $10 \%$ of Sicily's GDP originates from oil refining, an activity in significant decline due to the dramatic decrease of oil consumption in Italy started in 2008. For comparison, the amount of oil entering Sicily's ports to undertake refinement went from 28.76 million tons in 2010 to 24.57 million tons in $2016(-14.6 \%) .{ }^{[65]}$ Since then, it has continued to diminish.

Along with new natural product extraction and solar energy 
technologies, catalysis (and heterogeneous catalysis in particular) is the key technology enabler of the bioeconomy and the related new chemical industry. ${ }^{[6]}$

Due to low operational and capital expenses, today's new production routes to valued chemicals and bioproducts based on new catalytic and new extraction technologies are eminently suited to establish new economic activities in developing regions and countries.

We empirically know today that international scientific cooperation and access to the best research is key for scientific and technological progress. ${ }^{[6]}$ Fostering international collaboration and practically useful progress in frontier research, scientific meetings on topics of socioeconomic and environmental relevance, such as the FineCat symposia briefly reviewed in this study, are an useful tool to proactively promote sustainable development in its full economic and social dimension in developing areas of the world.

\section{Acknowledgement}

This work is dedicated to Professor Raed Abu-Reziq, Hebrew University of Jerusalem, for all he has done to advance the synthesis of fine chemicals via new generation sol-gel catalysts in the course of the last decade. The fruitful collaboration of Catalysis Science \& Technology, RSC Publishing, as publishing partner of the FineCat symposia is gratefully acknowledged. We are grateful to all participants of the FineCat symposia held in Sicily between 2012 and 2017, as well as to Piera Demma Carà, now at IOP Publishing, Marzia Sciortino, currently at CNR-ISMN, Giovanni Palmisano, now Associate Professor at Khalifa University of Science and Technology, Francesco Parrino, now at the University of Trento, Riccardo Delisi, now at Renovo Biochemicals, as well as to Emanuele Domina and Serafina Prestia, University of Palermo, for their support during the organization of the meetings.

\section{Author Contributions}

This paper was written through contributions of all authors. All authors have given approval to the final version of the manuscript.

\section{References}

[1] Pagliaro, M.; Hutchings, G. Catal. Sci. Technol. 2011, 1, 1543.

[2] Dumeignil, F. Designing Next Generation Biorefineries, International Forest Biorefining Conference 2017, Thunder Bay, Canada, May 9-11, 2017.

[3] Comotti, M.; Della Pina, C.; Matarrese, R.; Rossi, M. Angew. Chem. Int. Ed. 2004, 43, 5812.

[4] Rothenberg, G. A Simple and Effective Method for Predicting Catalyst Performance, FineCat 2012-Symposium for heterogeneous catalysis for fine chemicals, Palermo, Italy, April 18-19, 2012.

[5] Slater, J. C. Phys. Rev. 1930, 36, 57.

[6] Ras, E.-J.; Louwerse, M. J.; Rothenberg, G. Catal. Sci. Technol. 2012, 2, 2456

[7] Ras, E.-J.; McKay, B.; Rothenberg, G. Top. Catal. 2010, 53, 1202.

[8] Hutchings, G. J. Catalysis with Gold and Gold Palladium Nanoparticles, FineCat 2012-Symposium for heterogeneous catalysis for fine chemicals, Palermo, Italy, April 18-19, 2012.

[9] Hutchings, G. J. J. Catal. 1985, 96, 292.

[10] Haruta, M.; Kobayashi, T.; Sano, H.; Yamada, N. Chem. Lett. 1987, 16, 405.

[11] Kesavan, L.; Tiruvalam, R.; Hasbi Ab Rahim, M.; bin Saiman, M. I.; Enache, D. I.; Jenkins, R. L.; Dimitratos, N.; Lopez-Sanchez, J. A.; Taylor, S. H.; Knight, D. W.; Kiely, C. J.; Hutchings, G. J. Science 2011, 331, 195.

[12] Hughes, M. D.; Xu, Y.-J.; Jenkins, P.; McMorn, P.; Landon, P.;
Enache, D. I.; Carley, A. F.; Attard, G. A.; Hutchings, G. J.; King, F.; Hugh Stitt, E.; Johnston, P.; Griffin, K.; Kiely, C. J. Nature 2005, 437, 1132.

[13] Della Pina, C.; Falletta, E. Gold-Catalyzed Oxidation in Organic Synthesis: A Promise Kept, FineCat 2012-Symposium for heterogeneous catalysis for fine chemicals, Palermo, Italy, April 18-19, 2012.

[14] Prati, L.; Schiavoni, M.; Campisi, S.; Villa, A. Biomass Valorisation by Oxidative Processes, FineCat 2012-Symposium for heterogeneous catalysis for fine chemicals, Palermo, Italy, April 18-19, 2012.

[15] Pagliaro, M. Single-Atom Catalysis, Elsevier, Amsterdam, 2019.

[16] Herzing, A. A.; Kiely, C. J.; Carley, A. F.; Landon, P.; Hutchings, G. J. Science 2008, 321, 1331.

[17] Tyler McQuade, D. A Flow Chemistry Approach to Catalysis, FineCat 2013-Symposium for heterogeneous catalysis for fine chemicals, Palermo, Italy, April 10—11, 2013.

[18] Bogdan, A. R.; Poe, S. L.; Kubis, D. C.; Broadwater, S. J.; Tyler McQuade, D. Angew. Chem. Int. Ed. 2009, 48, 8547.

[19] Gilmore, K.; Kopetzki, D.; Lee, J. W.; Horváth, Z.; Tyler McQuade, D.; Seidel-Morgenstern, A.; Seeberger, P. H. Chem. Commun. 2014, 50, 12652.

[20] Longstreet, A. R.; Tyler McQuade, D. Acc. Chem. Res. 2013, 46, 327.

[21] Bianchini, C. Electrochemical Valorisation of Alcohols, FineCat 2013-Symposium for heterogeneous catalysis for fine chemicals, Palermo, Italy, April 10—11, 2013.

[22] Bambagioni, V.; Bevilacqua, M.; Bianchini, C.; Filippi, J.; Lavacchi, A.; Marchionni, A.; Vizza, F.; Shen, P. K. ChemSusChem 2010, 3, 851.

[23] Santacesaria, E. Glycerol as Raw Material in the Production of Chlorohydrins and tert-Butyl Ethers, FineCat 2013-Symposium for heterogeneous catalysis for fine chemicals, Palermo, Italy, April 10-11, 2013.

[24] Di Serio, M.; Casale, L.; Tesser, R.; Santacesaria, E. Energy Fuels 2010, 24, 4668.

[25] Santacesaria, E.; Tesser, R.; Di Serio, M.; Casale, L.; Verde, D. Ind. Eng. Chem. Res. 2010, 49, 964.

[26] Webb, P.; Kunene, T.; Hintermair, U.; Duque, R.; Coetzee, J.; Cole-Hamilton, D. Flow Catalysis Using Supported Homogeneous Catalysts, FineCat 2014-Symposium for heterogeneous catalysis for fine chemicals, Palermo, Italy, April 2-3, 2014.

[27] Coetzee, J.; Manyar, H. G.; Hardacre, C.; Cole-Hamilton, D. J. ChemCatChem 2013, 5, 2843.

[28] Cornforth, J. W. Chem. Br. 1975, 11, 342.

[29] Duque, R.; Pogorzelec, P. J.; Cole-Hamilton, D. J. Angew. Chem. Int. Ed. 2013, 52, 9805.

[30] Bérubé, F.; Kleitz, F.; Kaliaguine, S. Preparation of Ti-SBA-15 Epoxidation Catalysts, FineCat 2014-Symposium for heterogeneous catalysis for fine chemicals, Palermo, Italy, April 2-3, 2014.

[31] Bérubé, F.; Khadhraoui, A.; Janicke, M. T.; Kleitz, F.; Kaliaguine, S. Ind. Eng. Chem. Res. 2010, 49, 15, 6977.

[32] Fornasiero, P. Designing Catalysts of Clusters and Nanocrystals as Building Blocks, FineCat 2014-Symposium for heterogeneous catalysis for fine chemicals, Palermo, Italy, April 2-3, 2014.

[33] Cargnello, M.; Fornasiero, P.; Gorte, R. J. ChemPhysChem 2013, 14, 3869.

[34] Marchionni, A.; Bevilacqua, M.; Bianchini, C.; Chen, Y.-X.; Filippi, J.; Fornasiero, P.; Lavacchi, A.; Miller, H.; Wang, L.; Vizza, F. ChemSusChem 2013, 6, 518.

[35] Cargnello, M.; Doan-Nguyen, V.; Gordon, T. R.; Diaz, R. E.; Stach, E. A.; Gorte, R. J.; Fornasiero, P.; Murray, C. B. Science 2013, 341, 771.

[36] Lopez-Sanchez, J. A. Opportunities and Challenges for Combining Chemo-Catalysis in Biomass to Chemicals Processes: A Critical Perspective, FineCat 2014-Symposium for heterogeneous catalysis for fine chemicals, Palermo, Italy, April 2-3, 2014. 
[37] Lopez-Sanchez, J. A. Chem. World 2014, 11, 45.

[38] Reetz, M. T. Directed evolution of enantioselective enzymes as catalysts in organic chemistry, FineCat 2015-Symposium for heterogeneous catalysis for fine chemicals, Palermo, Italy, April 8-9, 2015

[39] Reetz, M. T.; Tielmann, P.; Wiesenhöfer, W.; Könen, W.; Zonta, A. Adv. Synth. Catal. 2003, 345, 717.

[40] Reetz, M. T. J. Am. Chem. Soc. 2013, 135, 12480.

[41] Beletskaya, I. P. From Homogeneous to Heterogeneous Catalysis in Fine Organic Synthesis, FineCat 2015-Symposium for heterogeneous catalysis for fine chemicals, Palermo, Italy, April 8-9, 2015.

[42] Ananikov, V. P.; Beletskaya, I. P. Organometallics 2012, 31, 1595.

[43] Kappe, C. O. Towards the Synthesis of APIs in Continuous Flow Mode, FineCat 2015-Symposium for heterogeneous catalysis for fine chemicals, Palermo, Italy, April 8-9, 2015.

[44] Gutmann, B.; Cantillo, D.; Kappe, C. O. Angew. Chem. Int. Ed. 2015, 54, 6688.

[45] Rodrigo, O. M.; de Souza, A. Medicines for All: A Brazilian Perspective, FineCat 2015-Symposium for heterogeneous catalysis for fine chemicals, Palermo, Italy, April 8-9, 2015.

[46] Silva, M. V. M.; Bassut, J. F.; Junior, I. I.; de Souza, S. P.; Estrada, M. L. G.; Miranda, L. S. M.; de Souza, R. O. M. A. RSC Adv. 2015, 5, 102409.

[47] Paul, S.; Heyte, S.; Thuriot-Roukos, J.; Araque Marin, M.; Dumeignil, F. REALCAT: An Advanced High-Throughput Platform Dedicated to Biorefineries Catalysts Design, FineCat 2015Symposium for heterogeneous catalysis for fine chemicals, Palermo, Italy, April 8-9, 2015.

[48] Maireles-Torres, P. Heterogeneous Catalysis for the Oleochemical Platform, FineCat 2015-Symposium for heterogeneous catalysis for fine chemicals, Palermo, Italy, April 8-9, 2015.

[49] Mäki-Arvela, P. Catalytic Synthesis of Dioxinol Formed by Addition of a Monoterpenoid, Verbenol Oxide, with Benzaldehydes over Metal Modified Zeolites, FineCat 2015-Symposium for heterogeneous catalysis for fine chemicals, Palermo, Italy, April 8-9, 2015.

[50] Debecker, D. P. Original Sol-Gel Strategies for Successful Catalyst Preparation: from Bulk Petrochemistry to Green Chiral Synthesis, FineCat 2015-Symposium for heterogeneous catalysis for fine chemicals, Palermo, Italy, April 8-9, 2015.

[51] Van den Biggelaar, L.; Soumillion, P.; Debecker, D. P. Catalysts 2017, 7, 54.

[52] Ananikov, V. P. Heterogeneous Catalysis in the Eyes of Fine
Organic Chemists: Selective Formation of $\mathrm{C}-\mathrm{C}$ and $\mathrm{C}-$ Heteroatom bonds, FineCat 2016-Symposium for heterogeneous catalysis for fine chemicals, Palermo, Italy, April 6-7, 2016.

[53] Ananikov, V. P. ACS Catal. 2015, 53, 1964.

[54] Pentsak, E. O.; Kashin, A. S.; Polynski, M. V.; Kvashnina, K. O.; Glatzel, P.; Ananikov, V. P. Chem. Sci. 2015, 6, 3302.

[55] Sels, B. Novel Advancements in Lewis Acid Catalysis with Sn, FineCat 2016-Symposium for heterogeneous catalysis for fine chemicals, Palermo, Italy, April 6-7, 2016.

[56] De Clercq, R.; Dusselier, M.; Christiaens, C.; Dijkmans, J.; lacobescu, R. I.; Pontikes, Y.; Sels, B. F. ACS Catal. 2015, 5, 5803.

[57] Ennaert, T.; Van Aelst, J.; Dijkmans, J.; De Clercq, R.; Schutyser, W.; Dusselier, M.; Verboekend, D.; Sels, B. F. Chem. Soc. Rev. 2016, 45, 584.

[58] Grader, G. S. Mesoporous Ceramic Nanofibers for Heterogeneous Catalysis, FineCat 2017-Symposium for heterogeneous catalysis for fine chemicals, Palermo, Italy, April 5, 2017.

[59] Elishav, O.; Beilin, V.; Shter, G. E.; Dinner, O.; Halperin, V.; Grader, G. S. J. Am. Ceram. Soc. 2017, 100, 3370.

[60] Hashmi, A. S. K. New aspects of gold catalysis, FineCat 2017-Symposium for heterogeneous catalysis for fine chemicals, Palermo, Italy, April 5, 2017.

[61] Hashmi, A. S. K.; Schwarz, L.; Choi, J.-H.; Frost, T. M. Angew. Chem. Int. Ed. 2000, 39, 2285.

[62] Abu-Reziq, R. Nanostructured Materials, Nano- and Microreactors as Platforms for Heterogeneous Catalysis, FineCat 2017Symposium for heterogeneous catalysis for fine chemicals, Palermo, Italy, April 5, 2017.

[63] Abu-Reziq, R.; Batarseh, C.; Weiss, E.; Abu-Reziq, R. Metal Nanoparticles Supported on Magnetically Separable Materials In Nanotechnology in Catalysis, Eds.: Van de Voorde, M.; Sels, B., Wiley-VCH, Weinheim, 2017, pp. 179-207.

[64] Italy's National Institute of Statistics, Italy GDP per Capita, 2018 See at the URL: www.ceicdata.com/en/italy/esa-2010-gdp-percapita-by-region/gdp-per-capita-is-sicily.

[65] Assessorato regionale dell'energia e dei servizi di pubblica utilità, Rapporto energia 2017, Palermo, 2018. See at the URL: shorturl.at/ aqruB.

[66] Pagliaro, M. Angew. Chem. Int. Ed. 2019, 58, 11154.

[67] laria, A.; Schwarz, C.; Waldinger, F. Q. J. Econ. 2018, 133, 927.

Received August 10, 2019 Accepted August 17, 2019 